DATED: September 2009

Note: this conference paper was prepared for the September 2009

$37^{\text {th }}$ Telecommunications Policy Research Conference (TPRC 37).

\title{
Undue Process: Challenges for Rightsholders and Service Providers Implementing Section 512's Notice and Takedown Provisions
}

\author{
Jennifer M. Urban and Laura Quilter ${ }^{1}$
}

This paper empirically examines the 17 U.S.C. $\S 512$ notice and takedown process as implemented by the Texas online service provider, The Planet. We reviewed a random sample of notices from a population of all notices processed by The Planet from August 2004 to June 2007. We used a mixed methodology, qualitatively assessing the notices, and running quantitative checks to ensure that we were not mistakenly over- or understating the importance of qualitative findings. Because the notices most clearly show sender behavior, we focus on senders' use of section 512; we then more generally discuss the possible effects of sender behavior on targets and OSPs. We conclude that section 512 continues to be useful for copyright holders; in addition, it undoubtedly provides important innovation-promoting protection for intermediaries. Yet the section 512 regime also shows serious strain in practice, at least within our observed set of notices. A considerable group of senders have difficulty following section 512's technical requirements and understanding the substantive underlying copyright law. Further, as expected, the large copyright industries appear to be challenged by peer-to-peer filesharing - a problem for which the notice and takedown framework does not provide immediate relief-leading them to make broader demands than are supported by section 512. Finally, the emerging dominance of third-party rights enforcement organizations ("REOs") and trade associations, which have incentives to generate notices and achieve takedowns, add a layer of complexity to the process. Ultimately, these strains, and senders' responses to them, likely affect both OSPs and targets. Overall, they prompt concerns about due process for targets and potential harms to Internet expression. We reaffirm our previous suggestions for reform, and call for greater information sharing and transparency to help rebalance and strengthen the section 512 process.

\footnotetext{
${ }^{1}$ Assistant Clinical Professor of Law, UC-Berkeley School of Law, and Consultant, respectively. We are grateful for funding support from the Block v eBay cy pres fund and the Glushko-Samuelson Foundation and for research assistance and coding by student researchers Melody Akbari, Brianna Dahlberg, Christy England, Victoria Glinskii, Jonathan Housman, and Erin Reed. We are also deeply indebted to the Chilling Effects crew generally, and to Wendy Seltzer in particular, as well as to The Planet Internet Service for enabling the creation of this dataset.
} 


\section{Introduction}

In 1998, in hopes of updating copyright law for the world of the networked computer, Congress passed the Digital Millennium Copyright Act (the "DMCA"). In doing so, Congress fundamentally shifted the way interested parties dealt with alleged infringements of copyright on the Internet. Previously, parties had gone to court to enforce copyrights against allegedly infringing material on Internet sites. The DMCA's new section 512 notice-and-takedown regime, however, promoted the use of simple "takedown" notices from a copyright holder to the Online Service Provider ("OSP") where the allegedly infringing material (or for search services, index links to the allegedly infringing material) resided. ${ }^{2}$

It has now been more than a decade since the DMCA's passage. In that time, the world has changed. In 1999, before the DMCA even took effect, Napster launched and peer-topeer filesharing began to gain popularity with users, rendering obsolete section 512's assumption that infringing files usually would be hosted on a centralized OSP platform. In ensuing years, the world changed further. Some OSPs are now flooded with automatically generated form notices - whereas in 2006 we were able to study all of the 734 notices Google had received ${ }^{3}$ for its search services through August 2005, ${ }^{4}$ today Google receives about 2.4 million notices a week. And relatedly, whereas in 2006 the process of sending, receiving, and responding to notices was not yet highly automated, today notices may be form documents generated and responded to by algorithmic "robots." Each of these developments raises questions about the costs and benefits for copyright holders and OSPs, due process for targets, and effects on Internet expression.

We chose to study section 512 because it creates a structured (if complicated) regime that affects high-stakes activities such as expression and competition, and because it is an important plank in the regulatory infrastructure that governs Internet communications. The essential process established by section 512 - statutorily prescribed private notice of an alleged offense to an intermediary, rather than directly to the offender, followed by "takedown" of the challenged material - is currently unique to copyright law, but is regularly proposed as a solution for other kinds of online "speech problems," such as harassment and defamation, ${ }^{5}$ thus lending further importance to understanding its costs

217 U.S.C. 512.

${ }^{3}$ With the exception of notices Google rejected out of hand, before even sending them on to Chilling Effects.

${ }^{4}$ Jennifer M. Urban and Laura Quilter, "Efficient Process or 'Chilling Effects'? Takedown Notices under Section 512 of the Digital Millennium Copyright Act," 22 Santa Clara Computer \& High Technology Law Journal, 621 (2006) (hereinafter "Urban and Quilter 2006")

5 See, e.g., Michael Rustad and Thomas Koenig, "Rebooting Cybertort Law", 80 Washington L. Rev. 335 (2005), available at http://papers.ssrn.com/sol3/papers.cfm?abstract_id=961885 (proposing notice-andtakedown regime for tortious speech generally). See also Danielle Keats Citron, "Cyber Civil Rights", 89 Boston U. L.Rev. 61-125 (2009), available at http://papers.ssrn.com/sol3/papers.cfm?abstract_id=1271900 (assessing a notice-and-takedown regime for harassing speech and suggesting ways to implement one effectively). 
and benefits. In this third study in a series, ${ }^{6}$ we look at section 512 correspondence between notice senders and a hosting and connectivity provider.

\section{Background}

Section 512 of the Digital Millennium Copyright Act provides safe harbor from some secondary copyright liability for online service providers ("OSPs"). In return, OSPs must create and follow a policy to terminate service relationships with "repeat infringers," and, when providing hosting or search services, take down allegedly infringing material upon receipt of a notice from the copyright holder. In order to comply with the statute and trigger a takedown, the notice must meet various requirements intended to ensure that the complainant owns or controls the copyright in question, that infringing material is accurately identified, and that the notice is truthful and sent based on a good faith belief of copyright infringement. Depending on the service being provided, an OSP's obligation to remove material varies: the OSP has no obligation to remove materials traveling through its network as transitory network communications, but it must, in order to receive the safe harbor, "expeditiously remove, or disable access to" hosted materials or search index links.

Section 512 is intended to strike a balance that allows for infringing materials to be efficiently removed from the Internet, while protecting OSPs from the need to actively police their networks. In turn, the protection for OSPs is thought to protect Internet speakers and Internet expression by limiting OSPs' incentive to remove material preventively. To alleviate concerns about material being removed based on a mere allegation - a notice that does not receive any kind of judicial or administrative reviewthe statute requires the notice to include the identifying and attesting attributes listed above, and allows posters of targeted material to claim noninfringement by sending the OSP a counter notice. ${ }^{8}$ If the copyright holder does not file a lawsuit within ten days after the OSP receives a counter notice, the OSP may ${ }^{9}$ reinstate the links in the search index or the hosted content to the web page, blog post, video site, or other form of hosted content.

Since its implementation, the efficacy and the soundness of the section 512 takedown mechanism have been frequently debated. As a general matter, many OSPs clearly

\footnotetext{
${ }^{6}$ Urban and Quilter 2006; Laura Quilter and Marjorie Heins, "Intellectual Property and Free Speech in the Online World: How Educational Institutions and Other Online Service Providers Are Coping with Cease and Desist and Takedown Letters," a Public Policy Report from the Brennan Center of Justice (2007) (hereinafter "Quilter and Heins 2007").

717 U.S.C. $512(\mathrm{c})(1)(\mathrm{A})(\mathrm{iii})$.

8 There are limitations to this protection, particularly in the search context. Search index providers must remove links in order to receive the safe harbor, but are neither required - nor, in the absences of a service relationship, able - to let targets know about the takedown. 17 U.S.C. 512(d). Thus, any acceptance of "counter notices" is purely voluntary on their part.

9 The OSP receives an incentive to replace the materials - a safe harbor from liability to the target for removing it, in the first place. 17 U.S.C. 512(f). This is a rather weak incentive, since most OSPs foreclose the possibility of such liability in their terms of service.
} 
believe they have benefited from its protection, which severely limits liability for their users' copyright infringements ${ }^{10}$ - liability that otherwise could result in injunctions against the service and/or severe and unpredictable statutory damages. ${ }^{11}$ Ten years after the DMCA took effect, supporters of intermediaries declared it no less than "the Magna Carta for Web 2.0"12 for its role in encouraging new platform and intermediary innovation and investment. As such, the expression-supporting goal of the safe harbor would seem to be met by this result. At the same time, there are costs to section 512's mechanism. Requiring hosted materials or links to be taken down for ten to fourteen business days, based only on an extrajudicial notice, might overburden expression and result in inappropriate censorship. After all, it may be unrealistic to expect OSPs to use rigorous and costly screening mechanisms to sort weak or nonexistent copyright claims from strong ones, particularly as copyright analysis is famously fact-intensive and legally complex. On top of the immediate cost of doing a substantive review of a notice's claims, OSPs must weigh the potential liability costs of foregoing section 512's safe harbor if they leave up material that is later determined to be infringing. Accordingly, section 512 's structure is arguably biased toward takedown. ${ }^{13}$

Section 512 was also, in some respects, rendered out-of-date even as it took effect. The DMCA was negotiated and passed in 1998. In mid-1999, Napster launched, and in the ensuing months and years, the copyright industries' worries shifted from hosted material to material shared over peer-to-peer systems - for which OSPs act as "mere conduits" under section 512(a), and for which OSPs have no duty (or ability) to "take down," since the material resides out of OSP control on users' computers. In public statements, studios

10 The scope of this protection is regularly litigated. Large copyright holders have threatened and sometimes brought legal action against OSPs despite section 512, arguing, for example, that OSPs failed to meet section 512's safe harbor requirements, or are ineligible if they earn advertising revenue or have generalized knowledge of large amounts of infringement. See, e.g., Perfect 10, Inc. v. Cybernet Ventures, Inc., 213 F. Supp. 2d 1146, 1179-80 (C.D. Cal. 2002) (failure to accept "representative lists" of infringements rendered Cybernet ineligible for safe harbor); Viacom Int'l v. YouTube, Inc. et al, 1:2007cv02103 (S.D.N.Y. March 13, 2007). (plaintiffs arguing that earning revenues from infringement and knowing, as a general matter, that infringement is occurring on a large-scale renders YouTube ineligible for safe harbor). As this paper was being completed, however, one federal district court judge rejected these arguments and held that content platform Veoh was fully protected by 512's safe harbors. UMG Recordings v. Veoh Networks, Inc., 2:07-cv-05744-AHM-AWJ (C.D. Cal. Sept. 11, 2009)

11 See generally Pamela Samuelson and Tara Wheatland, "Statutory Damages in Copyright Law: A Remedy in Need of Reform," William \& Mary L. Rev., forthcoming; available at

http://papers.ssrn.com/sol3/papers.cfm?abstract_id=1375604 (discussing the severity and unpredictability of statutory damages).

12 Tim Wu, "How the Bell Lobby Helped Midwife YouTube," Slate, Oct. 26, 2006, at http://www.slate.com/id/2152264/fr/rss/ .

13 For one provider's affirmation of this issue, see YouTube, “General Copyright Inquiries: Using Some Copyrighted Content in Your Videos", at http://www.google.com/support/youtube/bin/answer.py?hl=en\&answer=143457 (last visited Sept. 24, 2009) ("Unfortunately we cannot make a determination whether your video qualifies as fair use. If you disagree with a copyright takedown notice that you have received, you may file a counter-notification.") 
and labels continue to lament their inability to control copyright infringement. ${ }^{14}$ More recently, the rise of inexpensive bandwidth and storage, coupled with ever-moresophisticated editing and publishing tools, has created a new explosion in hosted Internet content, as well. For the large copyright industries in particular, it has likely been difficult to keep up.. For example, before suing YouTube in March, 2007, Viacom provided notice to YouTube of what it alleged were 100,000 separate infringements. Citing such examples, copyright holders argue that section 512 is insufficient to help them police Internet infringement.

Although the process was designed to be inexpensive and easy for copyright holders, these problems of scale - which might affect both major copyright holders and the OSPs expected to evaluate the notices - merit attention. Further, major copyright holders generating massive numbers of notices, as in the YouTube example, prompts concerns about the quality of the underlying copyright investigation and claim; ${ }^{15}$ ex ante filtering by OSPs prompts even greater concerns. ${ }^{16}$ In addition, while the process of drafting and sending a notice is outlined in detail in the statute, our review of notices sent to OSPs reveals that many senders, including some professional rights enforcement agents, struggle to comply with the statutory requirements. ${ }^{17}$ Section 512 is complex and confusing to users, with its five distinct safe harbors, its multiple formal technical requirements, and its checks-and-balances and incentivizing schemes. ${ }^{18}$

Beyond the question of section 512's effectiveness for OSPs and for copyright holders large and small, section 512 poses risks to individuals' rights to use the Internet for expressive and other purposes. Section 512 authorizes removal of content before any claims are reviewed by a court of law_indeed, even if no such claims are ever filed. OSPs may not review the substantive merits of the claims, given the burdens it entails. Section 512 thus relies heavily on its built-in mechanisms to protect targets from undue burdens on expression. These mechanisms include the section 512(g) "counter notice and putback" provisions, backed up by the section 512(f) remedy for knowing, material misrepresentations by others in the process. However, simply to have their content returned to the Internet, targets bear the burden of complying with the rather complex

\footnotetext{
${ }^{14}$ For just one among many examples of industry statements on the need for more assistance to control copyright infringement, see Stephanie Condon, "Congress Looks Abroad to Curb Piracy", C|Net News, April 6, 2009, at http://news.cnet.com/8301-13578_3-10213367-38.html .

15 See, e.g., Expert Witness Report of Yongdae Kim, Capitol v. Thomas, March 3, 2009 (available at http://beckermanlegal.com/pdf/?file=/Lawyer_Copyright_Internet_Law/ virgin_thomas_090303DeftsExpertWitnessReport.pdf ); see also Nate Anderson, "MediaSentry Weighed in the Balance, Found Wanting", Ars Technica, March 5, 2009, at http://arstechnica.com/techpolicy/news/2009/03/mediasentry-weighed-in-the-balance-found-wanting.ars, reviewing various negative and positive claims about P2P investigation techniques.

16 These concerns were summarized in Reply Comments of Public Knowledge, Et Al., In the Matter of Broadband Industry Practices, WC Docket No. 07-52 Before the Federal Communications Commission (July 16, 2007), available at http://www.publicknowledge.org/pdf/pk-etal-fcc-07-52-20070716.pdf. .

${ }^{17}$ See discussion infra, passim. 18 Quilter and Heins at 19.
} 
statutory counter notice procedures, and there is no guarantee of "putback." To enforce section 512(f), targets are required to bring suit in a court of law. All the available evidence suggests that even when targets believe their content was fair use or otherwise not infringing they often do not understand or feel too intimidated to take advantage of their rights under section $512 .^{19}$

These issues of due process pose a potentially grave concern. Traditionally, a court, in a public proceeding, reviews copyright claims. Copyright analysis is heavily fact-based, requires the application of both caselaw and complex statutory rules, and requires considering which of copyright's many limitations and defenses that are applicable to the case at hand. The protections built in to the section 512 regime pale in comparison with review by a judge. ${ }^{20}$ As such, understanding how section 512 is used by copyright holders and intermediaries, and responded to by targets, is important to finding out whether its carefully constructed balance holds in practice, and whether it is working for its intended beneficiaries.

\section{A. Studying the 512 Process}

A review of the landscape sketched above prompts the following (very general) questions: What is the overall benefit to and burden of section 512 on OSPs? Is section 512 working as intended for copyright holders? What is the overall burden of section 512 on targets of notices, and more broadly, on Internet users and expression? In this paper, we evaluate aspects of each of these questions, but focus on the second: how section 512 is being used by copyright holders who send notices, and what we can tell about how it is working for them.

Evaluating the use of section 512 is complicated by a number of factors, foremost the fact that it essentially codifies a private-ordering system. Notices and counter-notices are not public; nor are any actions taken by OSPs in response to notices. To take the question regarding burdens on expression as an example, several high-profile court challenges to

19 See Heins 2006 (most "fair use" content removed was never replaced; focus groups with users and follow-up interviews with individuals whose content had been removed indicated little understanding of the substantive rights, and significant intimidation); Urban and Quilter 2006 (very few counter notices in study of Chilling Effects notices); Quilter and Heins 2007 (OSPs report receiving few counter notices). Similarly, we observed no counter notices in this study; however, our dataset focuses on The Planet's correspondence with senders, so this may simply be information we cannot observe.

20 The strongest protection for targets is section 512(f). Section 512(f) permits recovery of damages and attorney's fees for wrongful takedown, and a limited number of section 512(f) cases have awarded damages. The standard is a high one, however: the original complainant must have knowingly made a material misrepresentation. A targeted user must first actually take a section 512(f) action to court, no small hurdle itself, and then show a knowing and material misrepresentation. The small number of section 512(f) cases that have been brought have split, with some cases finding material misrepresentations (Online Policy Group v. Diebold, 337 F.Supp.2d 1195 (N.D. Cal. 2004); Lenz v. Universal, 572 F.Supp.2d 1150 (N.D. Cal. 2008) (plaintiff stated a case for a section 512(f) violation); Biosafe-One, Inc. v. Hawks, 524 F.Supp.2d 452 (S.D.N.Y. 2007); and just as many not (Rossi v. Motion Picture Ass'n of America, 391 F.3d 1000, 1004-05 (9th Cir. 2004); Dudnikov v. MGM Entertainment, Inc., 410 F.Supp.2d 1010 (D.Colo. 2005), and No. 00 CIV. 4660(SHS), 2002 U.S. Dist. LEXIS 16165, at 43-46 (S.D.N.Y. Aug. 29, 2002)). 
takedown notices $^{21}$, as well as anecdotal complaints by targets ${ }^{22}$ serve to illustrate the type of abuse that can occur, but these examples may be representative, or they may be highly unrepresentative. Most service providers decline to provide public information about the section 512 process and how they implement it. Empirical study seems to us the most likely to afford some sense of the overall health of the section 512 system, but without public records, the ability to develop complete datasets is limited.

Fortunately, a handful of service providers - notably, Google Inc., The Planet, and the Internet Archive - have elected to provide greater transparency than most. As it is impossible to do a comprehensive study of all notices sent, we have chosen instead to comprehensively study notices from some of these service providers. While this method can never provide a complete picture of copyright notice and takedown across the Internet, it can provide a series of useful snapshots into how it is experienced by some major participants.

The authors initially explored the use of section 512 in 2006, using a set of notices sent to the Chilling Effects Clearinghouse by Google Inc. and others. ${ }^{23}$ In addition, Quilter and Heins conducted an interview-based study of OSPs' interaction with section $512 .{ }^{24}$ The 2006 study focused on section 512's likely effects on targets, at least in the search context, by mixing quantitative and qualitative techniques to closely review the substantive quality of claims in notices. The 2007 study was a primarily qualitative review of OSPs' experience with section 512.

In this third paper we focus on a set of notices sent to The Planet, an ISP based in Texas that provides a variety of hosting services, collocation connectivity services, and has provided traditional connectivity services. As section 512 was drafted with primarily hosting and connectivity services in mind, ${ }^{25}$ this dataset offers us the important opportunity to go beyond our 2006 study, which was confined to search engine notices. ${ }^{26}$ In addition, The Planet dataset includes back-and-forth correspondence with sendersinformation missing from the 2006 study's dataset. This allows us to look more closely at senders' interactions with section 512 as implemented by a particular OSP.

21 Online Policy Group v. Diebold, 337 F.Supp.2d 1195 (N.D. Cal. 2004); Lenz v. Universal, 572 F.Supp.2d 1150 (N.D. Cal. 2008).

22 See generally Heins 2006 for discussions with targeted users.

23 Urban and Quilter 2006.

${ }^{24}$ Quilter and Heins 2007.

25 See generally Jessica Litman, Digital Copyright: Protecting Intellectual Property on the Internet (2000) for legislative history of the DMCA. For a more recent and briefer review of the history, see Jerome $\mathrm{H}$. Reichman, Graeme B. Dinwoodie, and Pamela Samuelson, "A Reverse Notice and Takedown Regime to Enable Public Interest Uses of Technically Protected Copyrighted Works", Berkeley Technology L. J., forthcoming, available at http://papers.ssrn.com/sol3/papers.cfm?abstract_id=1007817 .

26 Urban and Quilter 2006. 
We focus on five key topics, chosen for their usefulness in developing insight into senders' experience with the 512 process, and for their amenability to study via our current Planet dataset:

1) Use of 512(c) by Copyright Holders. How are different classes of copyright holders using section 512(c)? Are small copyright holders using it, and using it effectively? Are large copyright industries (which had a seat at the table crafting section 512) using section 512(c), are they using it effectively, and can we tell whether they are getting the benefit of their bargain?

2) The Shift to Peer-to-Peer and the Ensuing Use of "512(a)" Notices. Given the shift to peer-to-peer technologies described above, how often do copyright holders send "takedown notices" where the broad section 512(a) safe harbor (rather than the safe harbors premised on takedown) actually applies, and what are the characteristics of those notices? Based on our previous interviews and anecdotal examples, we expected to find a significant number of these notices, and expected them to be sent on behalf of large copyright owners. Qualitatively, we hoped to gain a deeper understanding of how these notices are used and processed, how they affect intermediaries and targets, and whether they are effective for senders..

3) Third-party Rights Enforcement Organizations and Trade Associations. In recent years, Internet investigation and enforcement services have proliferated; many trade associations have also taken on these roles. Given anecdotal evidence from our previous study, we expected to find a substantial number of notices sent by third-party agents on behalf of copyright owners, and hoped to develop an understanding of these notices' characteristics and how REOs and trade associations approach the takedown process.

4) Senders and the Complexity of Section 512. Although sending a notice is, in theory, inexpensive and easy, section 512 is notably complex to understand and implement, as is the underlying copyright law. We hoped to gain further understanding of how this complexity appears to affect (or not affect) the use of 512 by senders, and how their behavior might affect OSPs and, if possible, targets.

5) Senders and the Convenience of Section 512. Our 2006 study revealed a substantial amount of use of the section 512 regime by complainants with exclusive, primary, or supplementary non-copyright concerns. We expect this may be because 512's notice and takedown process is an attractive substitute for the lack of takedown processes in other areas of the law. We sought to broadly quantify, and qualitatively examine, this phenomenon as experienced by a hosting provider. 


\section{Data and Methodology}

As noted, the section 512 system is difficult to study. In general, 512 notices are not a matter of public record except in limited instances, when they become part of a court record via specific litigation; actions taken in response to the notices are likewise private. We are fortunate to have access to several relatively complete sets of notices received by major service providers at various periods within the last ten years.

In this paper, we focus on a set of notices submitted to The Planet, a Texas-based web host and Internet access provider. The Planet is thus far the only hosting and connectivity OSP that has been willing to provide us — and the public Chilling Effects project — with the notices it receives. Fortunately, we believe The Planet to be a reasonable exemplar. Based in Texas, it offered regional connectivity services during much of the time period we observed, ${ }^{27}$ and provides hosting and colocation services worldwide. It hosts 15-16 million websites and manages 48,500 servers as part of its managed hosting service. ${ }^{28}$ As it was until recently a mid-sized general connectivity provider and is a large hosting provider, The Planet provides a useful example of OSPs' interactions with section 512.

At the same time, of course, reviewing notices received by The Planet, or any individual service provider, cannot give us definitive answers about the overall use of section 512: The Planet or its customers may have characteristics that differ from other mid-sized providers or from very large national providers. For example, some notice senders may target much larger connectivity providers, or other hotspots (such as universities) in hopes of concentrating their efforts to forestall filesharing. Further, by submitting its notices to the Chilling Effects project, The Planet may be signaling a more transparent approach than other providers, which in turn may affect its policies or its attractiveness to notice senders. Despite these limitations, we think The Planet can give us a useful snapshot of the section 512 regime, which we can then compare to other information or use to prompt more pointed questions.

The population of notices in our database comprises 6,366 notices sent to The Planet from September, 2004 to June, 2007 and uploaded into a MySQL database hosted at ChillingEffects.org. Coding all 6,366 notices for would be prohibitively labor intensive and time consuming; therefore, for this paper, a random sample of 451 notices was extracted from the entire population for coding. To "code" the notices, we set up a MySQL database to track information about the parties (senders, copyright holders, and targets) and about the notice itself (date, relationship of sender to owner, relevant DMCA section, services targeted, and description of alleged infringement). To pull data from the

\footnotetext{
27 The Planet began phasing out connectivity services in 2006. See Dwight Silverman, "Nobody's Internet: EV1 says buh-bye-now to dialup users", Houston Chronicle TechBlog, Oct. 30, 2006, at http://blogs.chron.com/techblog/archives/2006/10/nobodys_interne.html .

28 Note that these are the latest numbers available on The Planet's website. See http://www.theplanet.com/about/. During the time period we observed, the numbers may have been somewhat different, of course.
} 
database, we used MySQL queries both of the random sample of coded data and of the full text of the larger notices database. For most queries, we calculate the margin of error to be $4.45 \%$, at a $95 \%$ confidence level. We used a mixed methodology in evaluating the notices in our sample, qualitatively assessing the notices, and running quantitative checks largely to develop a sense of scale and to ensure that we were not mistakenly over- or understating the importance of qualitative findings. We discuss example notices throughout; these notices are identified by their Notice ID in the Chilling Effects database, where published notices may be viewed. ${ }^{29}$

As previously mentioned, some of the notices in our set were actually a series of multiple notices, part of a chain of communications. We chose to count each chain of communications as a single notice. Because we treat each chain - no matter how much back-and-forth communication it represents - as one "notice," our analysis may underestimate the amount of time and effort The Planet puts into processing notices.

\section{Results and Analysis}

\section{A. Section 512(c) Notices Are Used by Copyright Holders}

Section 512(c), which governs the takedown of materials hosted "on systems or networks at the direction of users" - is the very heart of the statute, and those notices that fall squarely within section 512(c) are instructive in understanding the utility of the system for senders. We do find robust evidence that section 512(c) is used by a broad range of copyright claimants - 332 notices, or $74 \%$ of our sample, request the takedown of hosted materials. In addition, despite the shift to peer-to-peer filesharing after section 512 was crafted, large copyright holders make use of section 512(c) challenge hosted materials.

Based on their widely reported concerns about filesharing, and the heavy use of section 512(a) notices reported by OSPs by Quilter and Heins 2006, we anticipated that large copyright holders might not use section 512(c) as much as anticipated by its drafters; and even that they might instead primarily concern themselves with peer-to-peer filesharing. As our 2006 study focused on Google, primarily a search provider covered by section 512(d), it could not tell us much about whether section 512(c) was being used by large copyright holders, as intended. In the 2006 study, we observed relatively few notices from large copyright holders - due, almost certainly, to the fact that Google's search index was not a primary target for large copyright holders at that time. ${ }^{30} \mathrm{We}$ did anticipate, based on their significant presence in the 2006 study, that small copyright

\footnotetext{
${ }^{29}$ Published notices may be viewed publicly; unpublished notices may be viewed on request. Unfortunately, most of the notices had not yet been published at the time this paper was being prepared.

30 We discuss the reasons why this might be in our 2006 paper at 649-655. In short, smaller business may be especially concerned about search rank, and less-sophisticated senders may see takedown from Google as, basically, takedown from the Internet.
} 
holders would be a significant presence here, too, and perhaps the most significant presence in the section 512(c) dataset.

In fact, we see a significant portion (247 of 332, or 74\%) of section 512(c) notices from major copyright industries (music recording, film, software, publishing) in The Planet's population of notices. If The Planet is representative, it seems that large copyright holders do use section 512(c), and in the original context in which it was passed - taking down material from general hosting providers. ${ }^{31}$ Like section 512 (a) notices, section 512(c) notices in our set are sent primarily by trade associations and rights enforcement agents, whose 154 notices comprise $47 \%$ of the total section 512(c) notices in our random sample.

The movie and recording industries sent $65(20 \%)$ and $51(15 \%)$ of the total set of 332 512(c) notices, respectively. Other significant copyright holders in the entertainment industry include the pornography industry, which, via Steve Easton, Titan Media, and more infrequent senders sent 54 (16\%) of the total set of $332512(\mathrm{c})$ notices. The gaming industry sent 28 notices ( $8 \%$ of the 512 (c) set). The remaining notices $(134$, or $40 \%)$ were sent by smaller players, individual rightsholders, and a small number of one-off notices sent by less-prominent REOs and trade associations on behalf of large copyright holders. Although there are many of these smaller individual rightsholders in the dataset, each of them sends many fewer notices (one notice on average) than the large copyright holders.

We suspect that one reason (beyond the search index issue) we see so many more notices from large copyright holders here than in the 2006 study, is the fact that The Planet and Google each offer different types of hosting services. Google's section 512(c) notices primarily related to its Blogger service, which provides turnkey hosting for personal and individual blogs of all sorts. Thus, many of the complaints sent to Google Blogger were from other individual bloggers, complaining of content copied to another individual's blog, or to a linkfarm. The Planet, by contrast, is a full-featured webhost; it hosts a wide variety of content beyond blogs; it provides enterprise-level hosting as well as individualized hosting; and has customers who run online discussion forums, businessoriented warez sites, and other sites directed to multiple users. Distribution on such sites may be more likely to attract the attention of large copyright holders in the first place, and may provide more "bang for their buck" in enforcement actions.

As such, if The Planet is representative, section 512(c) is frequently used by copyright holders of all stripes, which is one sign that it is working as intended. Unfortunately, we also discovered evidence of problems with the process, which we turn to now.

31 The recent rise of platforms specifically for hosting user-generated content (for example, YouTube, Vimeo and the like) clearly presents a new context in which section 512(c) has force. 


\section{B. Peer-to-Peer Filesharing and "512(a)" Notices}

When we were researching our 2006 paper, confidential interviews with service providers revealed that they were receiving large numbers of "takedown" notices complaining of peer-to-peer filesharing activity; we also discovered anecdotal examples of such complaints in the Chilling Effects data we were reviewing at the time. ${ }^{32}$ When Quilter and Heins conducted more in-depth interviews with service providers in 2007, OSPs complained of receiving "masses" of these (often automatically-generated) notices, which diverted their time and resources away from other pressing network concerns, such as spam and viruses. ${ }^{33}$ Our 2006 dataset focused primarily on notices sent to Google under sections 512(c) and (d), and told us little about the use of takedown notices in the filesharing context. Consequently, in this paper we review The Planet's notices for information about senders' uses of section 512(a) notices.

These notices are potentially important because they complain of activity not covered by section 512's takedown provisions, demand action where none is required in order for the OSP to receive safe harbor protection, and request OSPs to provide the very harsh remedy of cutting off user access to the Internet. In most (though not all) situations where peer-to-peer filesharing is the sender's concern, the OSP is acting only as a conduit, providing what 512(a) terms, "Transitory Digital Network Connections," and further defines as, "transmitting, routing, or providing connections." "34 For these types of connectivity services, the OSP simply receives safe harbor from liability-no "takedown" is required, or even possible, given that the OSP does not host or control the material in question. Rather, it resides on the user's computer, and merely travels through the OSP's network in a transitory fashion.

Given this, it may at first seem puzzling why copyright holders would incur the costeven if it is low - of sending notices in this situation. In the main, the use of 512(a) notices demonstrates a shortcoming for copyright holders in section 512's structure, which was negotiated just before the advent of widespread peer-to-peer filesharing. First, based on the plain language within many of the notices, it seems that copyright holders are attempting to give legally relevant notice of infringement. Second, our confidential sources at OSPs stated that the entertainment industries intended these notices to establish evidence that some users are "repeat infringers," triggering the OSPs' obligation to terminate their service relationships with targeted users and cut off their Internet access under section 512(i). ${ }^{35}$

\footnotetext{
${ }^{32}$ Urban and Quilter, 675 - 76. 33 Quilter and Heins at 17.

${ }^{34} 17$ U.S.C. 512(a).
}

35 Section 512(i) sets out the general conditions OSPs must meet in order to receive any of the 512 safe harbors. Among other items, it requires OSPs to have "adopted and reasonably implemented... a policy that provides for the termination in appropriate circumstances of... repeat infringers." What makes an account holder a 'repeat infringer' is contested, as is what is required for an OSP to "reasonably implement" the policy. 
Based on the above information, we expected to see a substantial number of received notices complaining of 512(a)-covered behavior - what we are terming "512(a) notices"-and that they would mostly be sent by the entertainment industries and other large copyright holders affected by peer-to-peer filesharing. That is indeed what we observed in our review of The Planet's notices. Of our random sample of 451 notices, 96 , or $21 \%$, of the notices examined were 512(a) notices. Extrapolated across the population, and taking into account our overall margin of error of $4.45 \%$, we can expect between 1051 and 1623 of these notices in the overall population of 6366 notices.

Further, the vast majority (nearly 94\%) of section 512(a) notices were sent either by rights enforcement organizations ("REOs") acting on behalf of copyright industry companies $(48 \%)$, or by trade associations acting on behalf of their industry members (46\%). Only a very few 512(a) notices were sent on behalf of companies other than large entertainment, software or game companies. ${ }^{36}$ Also as expected, section 512(a) senders were targeting users of popular filesharing software such as BitTorrent and eDonkey. Significantly absent from these senders is the Recording Industry Association of America (RIAA), which sent only one of the filesharing notices to The Planet.

Given that takedown is neither possible nor required, we reviewed the section 512(a) notices in our set to see if we could qualitatively understand what relief was being sought by copyright holders and how they used the process.

\section{A Rise in Automated Notices and Rights Enforcement Organizations}

First, at least for our dataset, large copyright holders delegated the investigation of peerto-peer filesharing and the ensuing notice procedure to outside providers or trade associations. An overwhelming majority of section 512(a) notices in our set were sent by either REOs or trade associations - REOs sent $48 \%$ of these notices, with trade associations tracking at 46\%. Together, these third-party intermediaries represented the vast majority of section 512 (a) notices-94\% of the notices. ${ }^{37}$

REOs are typically non-attorney agents of copyright holders, authorized to search for, investigate, and/or attempt to thwart or quell copyright infringement, through legal or

36 The remaining $6 \%$ were sent by various copyright owners, including a pornography company, the International Cricket Council, and a software company. These were too few (well within our margin of error) to indicate anything about the notices in the overall population.

37 REOs sent a large number of section 512(c) notices - true takedown notices - as well, but many 512(c) notices were also sent by rightsholders themselves or by their attorneys using non-automated processes. Although nine of the top ten repeat section 512(c) senders are REOs or trade associations, making them responsible for a large proportion of notices, there are also many individual rightsholder-senders: of 148 unique 512(c) notice senders, $131(88.5 \%)$ are rightsholder-senders, and $113(76.3 \%)$ of these were onetime senders. By contrast, REOs or trade associations send virtually all 512(a) notices. 
technological means. ${ }^{38}$ This relatively new industry thus takes on the burden of "policing the Internet" for the copyright industries. ${ }^{39}$

Both REOs and trade associations have investigative arms, and include investigation reports ("infringement reports") in their notices, and both rely on similar means of investigation - automated "bot" searching of content, presumably using keywords, filenames, or fingerprinting technologies. ${ }^{40}$

The central feature of automatically generated notices is the "infringement report." (See Figure 1.) These infringement reports typically include fields for characteristics of the file found (file name, path for the file, file size), identifying information about the user (the IP address, sometimes the user name), and information about the alleged infringement (the protocol used, dates, etc.) Some of this information is critical - the dates, for instance, can provide key information to ISPs seeking to determine which user was assigned the cited IP address at the time of the alleged infringement. Other frequently included information, such as the user name, protocol used, and search engine used, though interesting to researchers, are not germane to the section 512 notice.

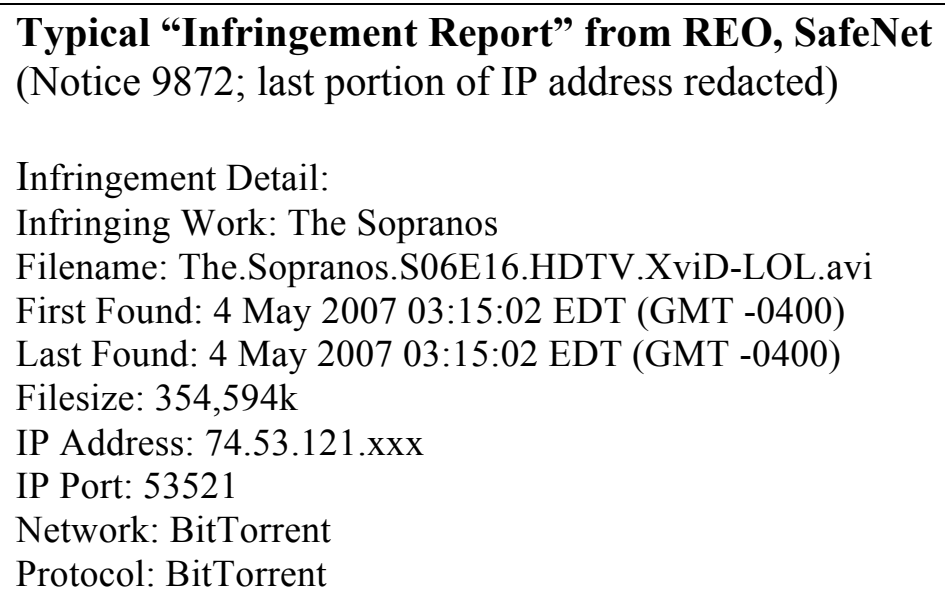

Figure 1: Typical "Infringement Report” from a rights enforcement organization.

38 To our knowledge, there is no industry-standard term for these organizations; we use the term "rights enforcement agents".

39 It also has achieved a certain degree of notoriety and criticism due to the tactics of MediaSentry, an REO employed primarily by the music recording industry. See generally Ray Beckerman, Recording Industry vs The People, a blog covering the recording industry's filesharing litigation.

40 Some of these intermediaries admit to or allegedly use a variety of more aggressive means to combat filesharing, including seeding filesharing networks with fake files or malware; setting up "honeypot" sites; and breaking into user computers or installing spyware on them. See, e.g., Jaikumar Vijayan, "MediaSentry defends work for RIAA in music piracy cases," ComputerWorld Security, Sept. 9, 2008, at http://www.computerworld.com/s/article/9114371/MediaSentry _defends_work_for_RIAA_in_music_piracy_cases. We do not here focus on these aspects of the efforts. 
Infringement reports are typically coupled with a form letter. The form letters typically cite the infringed work and the copyright holder - in our review REOs, in this instance, offered a more conforming notice than the trade associations, which not infrequently failed to list the copyright holder altogether, or simply cited their "members" as the copyright holders. The form letter typically requests the ISP to disable Internet access to the infringing file (which technically means disabling the subscriber's access more generally) and reminds the OSP of its obligation to terminate the subscriptions of "repeat infringers." (See Figure 2.)

Notice ID 10180 (BayTSP on behalf of NBC) "This unauthorized copying and distribution constitutes copyright infringement under Section 106 of the U.S. Copyright Act. Depending upon the type of service THEPLANET.COM INTERNET SERVICES is providing to this IP address, it may have legal and/or equitable liability if it does not expeditiously remove or disable access to the motion picture(s) listed below, or if it fails to implement a policy that provides for termination of subscribers who are repeat infringers (see 17 U.S.C. 512).....Please send us a prompt response indicating the actions you have takento [sic] resolve this matter, making sure to reference the Notice ID number above in your response."

Notice ID 12899 (Trade Association Entertainment Software Alliance on behalf of "one or more members") "Accordingly, ESA hereby requests ThePlanet.com Internet Services, Inc. to immediately remove or disable access to the Infringing Material at the URL address identified above."

Notice ID 7799 (BayTSP on behalf of Paramount) "We hereby request that you immediately remove or block access to the infringing material, as specified in the copyright laws, and insure the user refrains from using or sharing with others Paramount's materials in the future (see, 17 U.S.C. ?512 (sic))... Please responed (sic) indicating the actions you have taken to resolve this matter.

Notice ID 8619 (SafeNet on behalf of HBO) "Since you own this IP address (74.52.16.XX), we request that you immediately do the following: 1) Disable access to the individual who has engaged in the conduct described above; and/or 2) Take other appropriate action against the account holder under your Abuse Policy/Terms of Service Agreement.

Figure 2: Sample demand language from REOs and TAs.

As these examples illustrate, copyright holders (via REOs and TAs) use these notices to communicate their arguments concerning what OSPs" obligations should be ("remove or disable access;" "insure the user refrains for using or sharing with others...in the future;" "Disable access;" and "Take other appropriate action against the account holder under your Abuse Policy") and how section 512 should be read and applied. Some of these arguments - namely the demand to disable access based on infringing use of transitory connectivity services - have no real basis in the statute and must be viewed as an attempt to convince OSPs to comply despite their lack of obligation to do so. The very shape and 
style of the notices - which often invoke section 512 and track its formal requirementsact as rhetorical devices for pressing this interpretation of the statute. In addition, although takedown is not possible, if a sender can establish "repeat infringement" to the OSP's satisfaction, then that might trigger some OSP action, and could, at least, establish a record in the event of litigation.

\section{Broader Effects of Section 512(a) notices}

If the proportion of section 512(a) notices in our dataset is similar to the proportion of 512(a) notices received by other connectivity providers, then the practice of sending 512(a) notices clearly imposes on OSPs costs that were not bargained for when the deal that created 512 was struck. Twenty-one percent of overall notices received-more than a fifth - represents a significant increase in notices for OSPs to process above and beyond what is required of them by section 512. Our examination of individual notices showed that The Planet, at least, forwarded notices to its legal department for review (for example, Notice ID's 8089, 9602, and 13447); and researched the targeted IP addresses (for example, Notice ID's 10180, 10240, 10154 included responses from The Planet to the sender stating that the targeted IP address did not exist on its network). At the same time, it is impossible to tell just how significant a burden this is for The Planet; certainly, it and other OSPs complained of being inundated with filesharing notices when interviewed by Quilter and Heins, but whether filesharing notices represent a significant increase over what is expected generally for 512 compliance is less clear.

Especially given the costs 512(a) notices impose on OSPs, it is important to consider whether they provide some benefit for copyright holders. As noted above, 512(a) does not provide a takedown remedy for copyright holders - there is nothing to take down, as all complained-of material resides on individual computers beyond the ISP's controland sending 512(a) "takedown" notices to the ISP does nothing to change that. Yet if OSPs choose to cut off access to network services for targets, or terminate service relationships with them, then copyright holders have created a direct remedy against individual targets, and may have created a more general disincentive to filesharing.

Unfortunately, such a benefit for copyright holders would impose a heavy-and we think, disproportionate - burden on targets. Without knowing how OSPs respond to 512(a) notices, however, we cannot quantify the costs to targets, and unfortunately, we have little information about The Planet's practices with regard to targets of section 512(a) notices. No notices from The Planet to users were included in our random sample, and it appears that The Planet included only communications to senders in the information it turned over to Chilling Effects. ${ }^{41}$ Quilter and Heins, in their interviews with ISPs, discovered a range of responses to these notices, from no response, to tracking, to cutting

41 Some correspondence chains with senders referred to separate conversations The Planet had with users, but those conversations, themselves, were not included. It is possible that we do have these conversations in the larger population, but it is more likely that we received everything tied to the original section 512 notice and nothing else. 
off the user's access, at least temporarily. ${ }^{42}$ Over all, they found OSPs generally loath to completely block or terminate users, though some, especially universities, have acceded to this demands to varying degrees. ${ }^{43}$

The possible harm to expression and due process, in practice, tracks user harm, and is thus similarly difficult to quantify. As evidenced above by Notices 10180, 12899, 7799 and 8619, senders of section 512(a) notices, themselves, demand strong remedies, including cutting off the user's access to connectivity. If an OSP does not respond to a 512(a) demand to cut off connectivity, then the demand will have little effect on the target or the expression. ${ }^{44}$ If the OSP were to acquiesce to the demand, however, the effect on the target would be profound and the remedy disproportionate: a target could lose access to critical Internet services unrelated to the infringement.

As an additional concern, the bot identification of alleged infringers heavily relied upon by REOs has been the subject of much recent criticism, and raised as an issue in filesharing litigation, ${ }^{45}$ with targets protesting that they were not the people sharing the files, did not own the targeted music or movies, did not even own the computer in question, or were in some other way misidentified. To the extent these allegations are true, and the problems are reasonably widespread, they cast doubt on the ability of these systems to accurately identify potential infringements, and raise serious questions about the appropriateness of acting on the basis of these notices. Our dataset does not enable us to assess this question with any completeness, but we note that ten $(10 \%)$ of section 512(a) notices included internal notes from The Planet stating that IP address was not in their network (a phenomenon discussed in more detail below). This accords with anecdotal evidence from other service providers citing these sorts of identification difficulties. $^{46}$

While we venture no opinion as to the ultimate merits of the filesharing cases - or the behavior of the users targeted by these notices - we find such broad evidence of demands to cut off Internet access on a mere notice troubling. Further, unless they can convince OSPs to block targeted users' Internet access, or to terminate users' accounts entirely, section 512 does not provide a good mechanism for large copyright holders' attempts to reduce peer-to-peer filesharing. As such, section 512's protections for copyright holders have, in part, been left behind by newer technologies. In lieu of cooperation by OSPs, entertainment companies have turned toward "three strikes" approaches, both attempting

42 Some of the harshest measures - cutting off Internet access or access to certain network resources (usually temporarily) — were reported by universities acting as ISPs for their students. Quilter and Heins 2007 at $17-30$.

43 See generally Quilter and Heins 2007.

${ }^{44}$ It is possible that there is some effect. If the OSP forwards the notice to the target but takes no further action, the target could respond by removing the complained-of material. However, it is not known how often this more limited effect might occur.

${ }^{45}$ Capitol v. Thomas.

46 See generally Quilter and Heins 2007. 
to persuade lawmakers to implement such approaches legally and striking bargains with OSPs to implement such approaches as policy. We consider this further in the Discussion section, below.

\section{Rights Enforcement Organizations and Other Agents as Senders}

While 512(a) notices are the most dramatic example, the presence of copyright intermediaries such as trade associations and REOs is strongly felt in The Planet data set more generally. Overall, they were responsible for 249 notices in our sample - more than half (55\%) - including almost half the section 512(c) notices (154 of 332, or 46\%). Given their prominence, and their position as further intermediaries between targets and copyright holders, we consider these senders more generally, here.

There is a range of REO providers: in our random sample, we observed a total of 16 unique REOs; of these, five_-BayTSP; Steve Easton; James Young; NetResult; and NetEnforcers - sent the bulk of the REO notices in the sample. ${ }^{47}$ In this case, it is important to emphasize that these five senders represent only major senders to The Planet, and not their position in the industry as a whole-evidence suggests that individual REOs may focus on particular OSPs or classes of OSPs. ${ }^{48}$ From our sample of The Planet notices, and from the anecdotal evidence supplied by our earlier study of the Google notices, REOs are hired almost exclusively by large copyright holders - major labels, studios or production companies, software or game companies, or sometimes even trade associations, themselves.

Two of the more publicly well-known trade associations - the Motion Picture Association of America ("MPAA") and the Recording Industry Association of America ("RIAA") - have become known for their aggressive efforts to combat filesharing and copyright infringement; of these, perhaps surprisingly, the RIAA had very little presence in our dataset - only five notices in total, of which four were section 512(c) hosted content notices. $^{49}$ The MPAA is somewhat more apparent, with seven filesharing notices and three hosted content notices. The trade associations with the most significant presence in our random sample (together sending 84 of 451 notices, or 19\%) were the

47 GrayZone, MediaSentry, SafeNet, Web Sheriff each sent five or fewer notices in the sample; Cyber Cop, Cyveillance, Militis, Pal, and Jonathan Bailey each sent only one notice.

48 For instance, MediaSentry was mentioned regularly in interviews with universities in Quilter and Heins 2007, but was a minor sender in this dataset. We speculate that this characteristic may be due to REO's investigative techniques; for instance, they may choose (or program their bots) to investigate particular IP ranges or networks. Alternatively, the presence of different REOs in different OSP notice sets may result from the characteristics of REO's individual client bases - based on our limited information, most REOs, like trade associations, have clients drawn from a single industry. So, for instance, BayTSP, the most prominent REO sender in our dataset, represents the movie industry; Steve Easton, the second most prominent REO sender in our dataset, represents the porn industry; and GrayZone, one of the smaller REO senders in our dataset, represents the music industry.

${ }^{49}$ We cannot fully explain this, but the RIAA appears to focus many of its efforts on the higher education community. 
International Federation of the Phonographic Industry ("IFPI," a UK music trade association); the Entertainment Software Association ("ESA," a computer game trade association); and the Business Software Association ("BSA"). IFPI sent 25 notices, of which 23 targeted hosted content and only two targeted filesharing - in contrast with reports and anecdotal evidence about the American music industry group, the RIAA, which appears to primarily target filesharing. ${ }^{50}$ The computer games and business software trade groups targeted both filesharing and hosted content to a significant degree: ESA sent 40 notices, of which 23 targeted filesharing and 17 targeted hosted content; and BSA sent 19 notices, of which 11 targeted filesharing and eight targeted hosted content.

Although the vast majority of REOs in our sample represented traditional copyright industry companies, this is not true of all REOs. For example, Steve Easton of APIC Worldwide sent, on behalf of various pornography companies, $33(7 \%)$ of the notices in the sample. Easton is particularly interesting because, although his notices generally appear to target hosted material - proper subject matter for section 512 - and though they often (though not always) identified targeted materials with great specificity, they do not come close to following the 512(c) requirements for notices, and generally are quite cryptic. (See Appendix A.) (It took some work before we figured them out.) Therefore, a high proportion of his notices appear to have been rejected by The Planet - many include replies from The Planet stating that they do not comply with section 512 and that the complaint has not been forwarded. ${ }^{51}$ We discuss Easton's and other senders' struggles with the 512 structure in more detail below in section 3 .

The trade associations and the more professionalized REOs representing large media and software companies, on the other hand, used carefully crafted boilerplate language that conveyed their clients' legal positions about peer-to-peer filesharing and closely tracked section 512(c) formal requirements for notices. ${ }^{52}$ Yet, they also had problems with their notices. The Planet not infrequently noted that the complained-of IP address did not exist on its network. ${ }^{53}$ In one response to a BayTSP notice, on behalf of NBC, The Planet complained of a broader problem, asking BayTSP to "Note that as of today we still receiving complaints from IP addresses that it is [sic] not in our network. Please advise how we can fix this problem for good." ${ }^{, 54}$ Further, while these notices often closely tracked the formal statutory requirements, they also were sometimes quite vague about critical information, such as the copyright holder's identity. For example, the ESA routinely simply specifies "our members," as the copyright holder in question, as does the IFPI; in fact, at least 73 notices of our random set specified only "our members."

\footnotetext{
${ }^{50}$ See Quilter and Heins 2007. Easton before the response), 9297 and 14033. copyrighted work and allegedly infringing file.)

53 Examples include Notice IDs 10180 and 10240.

${ }^{54}$ Notice ID 10478.
}

51 Examples of these include Notice IDs 11625, 11128 (which also shows at least three notices from

52 See, for example, NoticeID 8879 (including "penalty of perjury" and "good faith belief" and identifying 
For the most part, however, the most striking observations about REOs and trade associations were their overall prominence as senders (56\% of notices) and the fact that they sent virtually all of the problematic section 512(a) notices. In Quilter and Heins's 2007 interview study of OSPs, OSPs complained that REOs sent "floods" of notices, which they compared to spam, and further complained that when there were problems with notices, REOs did not respond to complaints or attempts to address the problem. ${ }^{55}$ OSPs perceived these senders as creating a strain on the takedown system.

We cannot quantify any overall cost to The Planet, but we can see that REOs and trade associations are a significant source of its cost in processing notices. Extrapolating from our sample, we would expect to see somewhere between 3279 and 3851 notices from these senders over the three-year period we observed. ${ }^{56}$ Given The Planet's responses about mistaken IP addresses in 512(a) notices, it appears that, even when it is covered by section 512(a), The Planet, at a minimum, investigates which of its customers was using the IP at the time in question and, presumably, whether the customer was using a peer-topeer protocol. While we did not observe any 512(a) notices sent on to targets in The Planet data set, we know that some OSPs send them. ${ }^{57}$ By any measure, this is a significant cost for OSPs, particularly given that so many notices from these senders complain of activity that falls under the straight 512(a) safe harbor.

The cost to targets is even more difficult to quantify. As noted above, the cost to targets (and free expression values generally) related to 512(a) notices depends on how the OSP chooses to respond. At the same time, the position of these senders - as an additional third-party intermediary between the target and the copyright holder-may make it more difficult for targets to address mistaken or wrongful notices, especially if REOs are as unresponsive as OSPs complained. Further, as third party providers, REOs (and to a perhaps lesser extent trade associations) likely have incentives to send a large number of notices.

Given the significant amount of section 512 activity generated by REOs and trade associations, along with the rise of other similar services, such as Reputation Defender, we suggest further research to increase our understanding of their roles in removing material from the Internet.

\section{Senders and Section 512's Complexity}

One of the more striking of our qualitative observations is the extent to which senders struggled with the complexities of both the underlying copyright law and of section 512's specific requirements. Based on our observations in our 2006 Google study, we did

\footnotetext{
${ }^{55}$ Quilter and Heins, 14-17.

${ }^{56}$ These numbers might be somewhat high, given that The Planet began phasing out its connectivity services - the source of 512(a) notices-in 2006.

${ }^{57}$ See Urban and Quilter 2006 and Quilter and Heins 2007; the Chilling Effects database also provides examples.
} 
expect to see notices that failed to comply with 512's requirements, as well as notices that revealed a misunderstanding or misapplication of copyright law, made claims that sounded in areas of law other than copyright, or had other defects. In part because we were able to observe some back-and-forth correspondence between senders and The Planet, however, we developed a picture of the challenges section 512's technical structure, along with the complexity of copyright and other laws, presents for senders that was more qualitatively rich than we anticipated.

As a threshold matter, we note that we have not, for this paper, engaged in the deep substantive review of notices' underlying copyright claims that we did in our 2006 study. We are, however, quite comfortable that our qualitative observations give a genuine feel for the untidy and muddled manner in which senders attempt to implement the takedown process. For example, we ran a text-based search of both the random sample and the entire population as a check, picking up coded fields and our review notes on the notices for keywords related to noncompliant notices - this is a fairly rough technique, but the number of notices it picked up was sufficiently high (nearly half, not including the problematic 512(a) notices) that we feel very comfortable that sender confusion, mistake or over-aggressiveness is a meaningful issue in the dataset. Upon closer examination of notices in the dataset, we verified that notices suffer from the variety of defects noted above; many had multiple defects.

As an additional check, we reviewed our random sample and found that it contained 66 responses from The Planet stating that notices were not compliant and indicating that it would not take any action to report the claims to a target. (See Figure 3, "The Planet's 'does not substantially comply' response.") This generic "does not substantially comply" notice was sent only to section 512(c) senders - out of 332 total 512(c) notices, 66 included "does not substantially comply" notes back from The Planet; this translates to a bounce-back rate of about $20 \%$, leaving aside the definitionally problematic 512(a) notices. Further, while 18 of the "does not substantially comply" responses were to Steve Easton-of his total 33 notices in our set, more than half prompted this response from The Planet - removing him from the total still left other senders subject to a bounce-back rate of $16 \%$ (48 of 299 ) - almost one in six. ${ }^{58}$

Finally, we note that The Planet's "does not substantially comply" notices apparently are based solely on technical flaws, and do not reflect substantive flaws with the claims or potential defenses - in fact, The Planet notes in its form response that "we have not passed on the substantive merits of your claim."59

\footnotetext{
${ }^{58}$ By contrast, in our 2006 paper we found that "significant" statutory flaws marred approximately $9 \%$ of those notices, or only one in eleven.

${ }^{59}$ As we noted in our 2006 paper, "Takedowns based on notices with the significant flaws present significant burdens to the recipient OSPs and questions of fairness to the target. A complaint failing to identify the infringed or infringing works fails to make any genuine showing of a controversy, however limited the review of the merits of the controversy may be. Complaints that do not identify the location of the allegedly infringing work may result in over- or under- inclusive takedowns. The complainant contact information is important because alleged infringers have no way to respond with a counternotice if the OSP
} 
To Whom It May Concern:

Please note that below-referenced copyright infringement notice does not substantially comply with the required notification elements of the Digital Millennium Copyright Act of 1998

("DMCA").

Please note that we have not passed on the substantive merits of your claim.

Please visit our web site at http://www.theplanet.com/legal .

Legal Response Team

THEPLANET.COM INTERNET SERVICES, INC.

Figure 3: The Planet's “Does Not Substantially Comply” Response.

Overall, as we also observed in our 2006 study, senders appear to experience a significant amount of confusion around both the underlying legal rules and section 512's technical requirements. The following examples give an idea of the hodgepodge we observed. We found notices that did not "sound" in copyright (Notice ID 8504, complaining of illegally-distributed software product keys, Notice ID 12267, complaining of counterfeit watches, and Notice ID 8607, covering possible defamation and privacy claims). ${ }^{60}$ As suggested by the "does not substantially comply" responses from The Planet contained in the sample, we also found numerous examples of notices that did not include statutorily required information, including notices that did not sufficiently identify either the targeted information or the copyrighted material in question. Some notices were so vague as to effectively identify neither of these items (for example, Notice ID 14066, which appears to refer to copying of a web design, and Notice ID 12228, which refers to multiple top level domains as "carrying our copyrighted materials" (apparently, music)). In addition, we found a few notices that did not appear to come from the copyright holder or its agent (for example, Notice ID 14066, and Notice ID 13543, which offers, "A kid I know named Josh is hosting illegal Lineage 2 stolen server files on one of your hosts, the information for his server is: ...").

Beyond individual examples of claims, we particularly value the overall qualitative insight into senders' struggles to comply with the 512 regime (and The Planet's implementation of it) that we were able to obtain through the dataset. While we cannot tell from our data how common this is - it seems likely that a substantial number of senders never respond to a rejection - some senders engaged in lengthy back-and-forth with The Planet, attempting to understand how their notices fell short and what they needed to do to improve them. For example, the sender of Notice 9901 - included as the attached Appendix B - appears to grow increasingly frustrated with his inability to understand what his notice was missing, and with The Planet's nonspecific responses to

cannot reach the complainant.” Urban and Quilter 2006 at 674.

${ }^{60}$ Please see section IV.E, below, for a broader discussion of these non-copyright claims made by senders. 
his attempts to gain clarity. Although there might be further correspondence between this sender and The Planet that we do not have, we suspect that, in the end, he just gave up.

Even professional REOs sometimes struggled to comply. As described above, REOs representing large copyright holders most often had apparent problems with their automated investigatory techniques, resulting in notices identifying IP addresses not on The Planet's network. However, they also sent notices where the underlying claim did not sound in copyright (for example, Notice ID 10416, complaining of product keys on forums; Notice ID 13372, which appears to refer to linking or, possibly, signal theft); and notices that did not effectively identify the location of the allegedly infringing materials (for example, Notice ID 7599). Also as noted above, Steve Easton had particular problems; his notices were so cryptic that The Planet commonly rejected them. ${ }^{61}$

At times, Easton's struggles became dramatic. He sometimes sent notices several times (we counted up to nine times) before receiving a response from The Planet. At one point, after apparently sending a notification multiple times, he added this header to the top of his notice, "MORE THAN 1000 IMAGES and 50 NOTICES HAVE BEEN SENT TO THIS SITE. THEPLANET CONTINUES HOSTING AND FAILS TO COMPLY TO [sic] DMCA." (This is from Notice ID 12898.) In another instance, he invoked outside legal authority: "All images reside on THEPLANET's IPs. Copyright Management Tampering is a felony in the U.S. Once again your repeated failure to comply in a timely manner is forwardedto (sic) Texas State authorities." (This is from Notice ID 11997.) ${ }^{62}$

Of course, it may be that Easton did not care to improve his notices, or that he simply generated so many that it was not worth his time to fix them-but this seems somewhat unlikely, given his obvious frustration in the above examples. Further, the cryptic nature of his form notice (included as the attached Appendix A) seems unintentional, and some of his assertions (for example, "Steve Easton is a DMCA agent, NOT an attorney") reveal clear misunderstandings about section 512's requirements and vocabulary.

Though Easton, with his many notices, provides a particularly theatrical and rich example, his mistakes are of a kind with other senders' - others, too, struggle to identify the targeted content (for example, Notice ID 12484); misapply or neglect the formalities (numerous examples); seem to misapprehend the underlying law and/or section 512's tether to copyright law ${ }^{63}$ (for example, Notice ID 10781, which accuses Ed Magedson's Ripoff Report of defamation and extortion), or profoundly misunderstand the function and operation of section 512, generally (for example, Notice ID 7683, in which the sender

61 Despite the fact that our random sample likely did not pick up The Planet's response in numerous instances, of Easton's 33 notices, at least 18 (more than half) contained a note back from The Planet rejecting them.

62 Here, Easton also confuses section 1201 of the DMCA (the anticircumvention provisions, which do prohibit removing copyright management information, but which have nothing to do with the takedown regime) with section 512 .

${ }^{63}$ We offer more examples of these types of notices in section 4 , below. 
asks for takedown "So i do not have to submit a DMCA and get this all out of hand (sic))."

It should not be surprising that these profoundly complex statutes - the province of specialist lawyers - are hard to understand and easy to misapply. The extent of the confusion, however, raises questions about the overall efficacy of the takedown regime. It is hard to know how an OSP is meant to parse, much less substantively evaluate, some of the more confused notices in our data set_-given this, along with the fact that notices so often failed to meet section 512's basic technical requirements, it seems likely that some senders with meritorious claims do not receive the takedowns intended by the statute, and conversely, that some senders are making demands for takedown where section 512 ought not apply. Overall, the depiction that emerges from the data of senders' attempts to use section 512 is a sobering picture of broad confusion and misapprehension of the DMCA's requirements and the underlying substantive copyright law.

\section{E. Senders and Section 512's Convenience}

The examples above focus on general misunderstanding and lack of clarity; however, the subset of senders who, through mistake or intention, attempt to use the 512 takedown process to address non-copyright concerns are of particular interest. In our 2006 study, we observed that a significant number of senders (193 of 876, or 22\%), cited section 512 and copyright but explicitly or implicitly sought to address harms that "sounded" in other areas of the law, thus stretching section 512 well beyond its purpose. We were not surprised, therefore, to see this pattern in The Planet dataset, as well.

For instance, 63 of 451 (14\%) notices cited both trademark and copyright - many of these notices, however, actually appeared to reflect underlying concerns related only to harms other than copyright infringement. Typical is Notice 11666, which is entitled "Trademark \& Copyright Abuse By Apparent The Planet Customer", but which only discusses the trademark claim. ("I have discovered that one of your customers is apparently abusing our common law service marks...") Trademark claims also seemed to underlie the relatively common practice of claiming copyright infringements via product photos being used by (presumably unauthorized) resellers. As such, these notices claims "sounded" more in contract, or in some cases, counterfeiting or fraud. Others seemed focused on manufacturers' control over product resellers. For instance, in Notice 10227, NetEnforcers (an REO) sent (on behalf of Sony) a notice targeting an online electronics reseller offering Sony products, alleging that "The specific works, graphics or other material Sony believes to be infringed or to be the subject of infringing activity (the 'Infringing Material') are copyrighted images from Sony's website. Specific violations of copyrighted images by Tvsdepot.com are listed below this paragraph."

The online multiplayer game industry illustrates another approach taken by rightsholders seeking to control commercial offerings related to their products. In our data set, at least ten of the companies in the online multiplayer game industry sought to have sites dealing in game artifacts or "cheats" taken down. Here, the rightsholder may have a colorable 
copyright claim in some instances (perhaps related to the use of game characters or other creative game content); often, however, the essence of the claim is a contractual one: it is a violation of the game's terms of service. "Goldfarming", for instance, is a common "cheat" in which individual players generate "gold" or "experience points" in a game, and then sell those virtual points to other players for real world dollars. Game companies used takedown notices to object strenuously to sites offering "gold"; in one notice, Notice ID 9429, the game company's law firm condemned the practice on ethical as well as legal grounds, complaining that it harmed the gaming experience for other players (and thus caused economic harm to the gaming company):

The Website is being used to facilitate the offsite trading of RuneScape items and accounts and the distribution of software robots and / or similar programs (?"bots?" (sic)) for the purpose of cheating (as well as related discussion groups).

Clearly you or persons authorised by you have used our client?'s (sic) site to effect these transactions and you have thereby become bound by - and breached - our client?'s (sic) contract which strictly forbids such activities.

In any case you have tortiously induced the other parties to break their contracts with our client.

Amongst other things, real money trading carried out offsite enables some players to advance in the game by buying their way ahead. Bots also enable players to cheat at the game. Such activities spoil the game for the majority of honest players who just want to play it for the fun and challenge the game gives, if played fairly. Genuine players are deterred from playing. Consequently such transactions damage the game and cause our client financial loss.

Other typical notices include Notice ID 8873, in which the sender defines as the copyrighted work "The RuneScape logo", and describes the infringement as "The RuneScape logo and images of characters from within the RuneScape game are used prominently on the site, and clearly identifiable."

As to why these notices appear in the dataset to a significant degree, it again seems likely that some users are puzzled by the law and the process, and see the section 512 takedown procedure as the general method for complaining. Given the depth of confusion we saw on the part of some senders, this is likely the underlying problem in some cases.

More generally, however, the section 512 takedown process positions copyright infringements as one of the very few types of communications OSPs are required or incentivized to take down from the Internet. By contrast, most tortious speechviolations of privacy, defamation, harassment, unfair competition (though, notably, not intellectual property infringement) - is governed by section 230 of the Communications Decency Act, which provides blanket immunity to OSPs for their users' illegal speech. It seems likely that this broad immunity-which, unlike section 512, provides no incentive for OSPs to provide simple "takedown procedures" for complainants-encourages people 
to seek other means to redress wrongs or remove harmful speech from the Internet, including hanging claims on any available copyright hook in order to make use of section 512. Section 512 is simply too convenient and simple a process not to be leveraged for as many uses as possible, particularly when there are virtually no alternatives. ${ }^{64}$

\section{Discussion}

In general, our study demonstrates that the central feature of the section 512 notice and takedown regime - an efficient method for removing from the Internet infringing materials hosted by intermediaries - is likely to remain an important method in copyright holders' mix of approaches to infringement on the Internet. At the same time, section 512's imperfections are apparent: its complexity bewilders some senders, driving down the quality of notices; its convenient framework invites strained claims; and, with the advent of peer-to-peer filesharing, it fails to address a substantial concern of large copyright holders.

More specifically, over the course of our research into section 512, we have observed that a key problem for many senders attempting to use section 512 is not bad faith, per se, but confusion. This includes misunderstandings of copyright and other communicationrelated law; problems in following section 512's formal requirements; and confusion by all parties (including at times, OSPs) about how properly to implement the regime. The confusion, coupled with the fact that section 512's framework forces complex copyright questions through a simplistic decision-making process, results in some disorder. Some complainants are able to get content taken down despite weak underlying claims. ${ }^{65}$ Other complainants, sorely tried by difficulties with identifying whom to contact, properly formulating the notice, and understanding what they can request, fail to get the content removed even when they have legitimate claims. Given the strong speech interests embodied in Internet expression, these flaws in the system creates concern.

Notices sent to combat peer-to-peer filesharing, whether sent by copyright holders, themselves, or by REOs and trade associations represent another strain on the system. These notices create a wasteful cost for OSPs, with little obvious benefit to copyright holders unless OSPs agree to impose on targets the disproportionately strong remedy of disabling access to Internet services. At the same time, peer-to-peer filesharing poses a

\footnotetext{
${ }^{64}$ A possible addition to regimes that encourage takedown is the evolving law of secondary trademark liability - for example, the court in Tiffany v. eBay, 576 F.Supp2d 463 (S.D.N.Y. July 14, 2008) found that eBay's Verified Rights Owner (VeRO) Program - essentially a notice and takedown policy for trademark and other intellectual property violations, including but not limited to copyright - shielded it from contributory trademark liability, a result that might encourage other providers to create similar programs.

${ }^{65}$ In theory, weak claims would be met by a counter notification from the target under section $512(\mathrm{~g})$. We cannot evaluate how effective this protection is for targets of notices in our present data set, because we have only correspondence between The Planet and senders. If there were a substantial number of counter notices, and The Planet acted upon them, we think we would have come across at least some correspondence from The Planet back to senders, advising them of the counter notifications as set forth by section $512(\mathrm{~g})(\mathrm{B})$.
} 
serious challenge for the copyright industry, and section 512's limitations have caused more aggressive approaches to gain traction among copyright holders.

The first method takes the notice-and-takedown regime and steps it up several notches to a notice-and-cutoff regime. France's revised "three strikes" law, just passed as this paper was being revised, demonstrates this approach. Under France's statute, for instance, mere allegations can result not only in the removal of infringing content, but also in the disabling of the target's Internet connection. ${ }^{66}$ This approach is significantly harsher than content removal. First, it threatens to sweep up innocent bystanders. Internet subscriptions are rarely used just by one person; entire households commonly share them. Second, shutting off access to the Internet, poses harms, not just to targets' (and their households') expressive interests, but also to their ability to receive information, conduct business, and communicate with family and friends.

The second approach, increasingly common in the United States, and implemented in order to police both filesharing and hosted content, involves fingerprinting, filtering, and other automatic network monitoring techniques to detect potential copyright infringements. ${ }^{67}$ Automated detection (and in some cases, automated removal) runs the significant risk of mistake. The Planet's experience with notices targeted at material not on its servers illustrates. Moreover, by their very nature, automated methods can only detect similar or identical files; such technologies cannot assess the qualitative circumstances and other facts that establish a copyright claim or defense. And in general, automated network monitoring poses threats to individual privacy and information security.

Given the further risks they create for targets, these newer approaches could constitute solutions that are worse overall than the problem they address. Unfortunately-and despite the genuine challenges created for some copyright owners by filesharing - our review of the notices in this study suggests that the balance of harms created by notice and takedown is still tipped against targets. Although The Planet rejects a large number of notices for failure to "substantially comply" with section 512's requirements, other OSPs may not undertake this rigorous a review. Indeed, if the number of notices is sufficiently high, The Planet's level of review could prove impossible for OSPs without significant resources to invest. Further, OSPs, which lack the full context of the dispute, are in a poor position to fully evaluate the substantive underlying legal claims in a notice. If section 512 it is to fulfill its promise to be a neutral and effective dispute resolution

\footnotetext{
${ }^{66}$ See Nate Anderson, "France Passes Harsh Anti-P2P Three-Strikes Law (Again)", Ars Technica, Sept. 15, 2009 (at http://arstechnica.com/tech-policy/news/2009/09/france-passes-harsh-anti-p2p-three-strikes-lawagain.ars ); Austin Modine, "France passes three-strikes bill”, The Register, Sept. 15, 2009 (at http://www.theregister.co.uk/2009/09/15/ 
process for copyright infringement, it requires improvements that move away from filtering or "three strikes" mechanisms rather than toward them.

\section{A. Recommendations and Future Research Directions}

In our 2006 paper, we concluded with a number of recommendations that, if adopted, would mitigate the worst harms of section 512 while maintaining the best features of it. These generally were aimed at propping up the targeted user's rights - ensuring that users received notice of the allegation of infringement and the takedown request before takedown occurs, providing them greater opportunities to have content put back under section 512(g), strengthening section 512(f), and preventing OSPs from using their terms of service to undermine their statutory safe harbor incentive to put back content when appropriate.

Additionally, we recommended simplifying and streamlining the statute. The section 512(b) and 512(d) safe harbors and takedown procedures were, we felt, neither justified by copyright law nor necessary to protect copyright holders and OSPs, and we felt they ought to be replaced by 512(a)-like straightforward, unconditional safe harbors. We also recommended clarifying the definition of repeat infringers to prevent targets from losing their Internet access prior to being proved infringers in a court of law. In our view, these recommendations still generally hold. In light of our findings here, however, we additionally recommend the following:

First, Congress should allocate resources for, and the Copyright Office (or another institution designated by it) should develop and promulgate, additional consumereducation tools related to section 512. While some nonprofits do provide tools focused on the rights of consumers who are targeted by takedown notices, ${ }^{68}$ our observations of senders' struggles make it apparent to us that better-educated senders, armed with more information and easier ways to send compliant notices, might both send fewer problematic (overreaching, uninformative, non-copyright-based) notices, and have more success when they do send good (specifically targeted, narrowly focused, accurate and technically complete) notices. Senders would benefit by not wasting their time on notices unlikely to be successful, and by having their good notices properly processed by OSPs. In addition, should section 512(f) continue to grow teeth, they would more easily avoid stumbling into liability for sending problematic notices. These educational materials, including sample forms, could be part of a section 512 toolkit provided to OSPs and disseminated through the Copyright Office's website.

Second, and much more ambitiously, we call for a fundamental increase in the transparency of the section 512 regime in order to provide better information to participants. and to alleviate the additional concerns - on top of concerns prompted by takedown without judicial review_-provoked by the fact that notice and takedown is so

\footnotetext{
${ }^{68}$ See, generally, Fair Use Network (http://fairusenetwork.com/), Citizen Media Law Project, EFF's Bloggers Rights project.
} 
difficult to observe. Congress should require notice and takedown to be placed under public supervision, just as other statutory regimes are. Takedown notices, section $512(\mathrm{~g})$ counter notifications, and ultimate dispositions (was the material removed?) should be submitted to a central database, perhaps at the Copyright Office, where they may be reviewed by the public. Although entities like YouTomb, ${ }^{69}$ Chilling Effects, ${ }^{70}$ and the Citizen Media Law Project's Legal Threats database ${ }^{71}$ have made useful efforts to document this process, and while some OSPs have made commendable moves toward transparency, ${ }^{72}$ each of these endeavors are necessarily limited. While robust transparency of the kind we suggest might not directly influence notice claims, it would allow review of the process, inform metrics for how much clutter we can tolerate in the system, and suggest whether we need additional gatekeeping to sort the wheat from the chaff_-something more like that provided by a court—or whether intermediaries are still the best place for sorting to occur.

Finally, our study prompts further research in at least three key areas:

1) The role and methods of REOs and trade associations. What are the detection methods and how effective are they? Why do particular OSPs get targeted?

2) The role of competitors, particularly in new Internet-based business models (such as ad revenue and linkfarming schemes). As in our 2006 study, we observed competitors actively using section 512. How much of this activity reflects garden-variety copyright disputes, how much reflects attempts to gain competitive advantage, and do competitive incentives result in overly aggressive claims?

3) Further review of potential intellectual freedom and due process concerns, particularly those related to "notice and cutoff" regimes such as the one established by HADOPI, the new French law described above, and those related to fingerprinting and filtering systems. While the core expressive issues presented by these legal and technological developments continue to be of significant concern, their broader implications for access to information, personal communications, commercial development, and innovation need to be explored.

Lastly, we encourage further exploration of new approaches to resolving disputes arising from electronic communications and expression. Proposals to revise section 230's

\footnotetext{
${ }^{69}$ See http://youtomb.mit.edu.

${ }^{70}$ See http://www.chillingeffects.org

${ }^{71}$ See http://www.citmedialaw.org/database .

${ }^{72}$ See, e.g., Google, Blogger, ThePlanet, and Internet Archive, all of which submit notices to the Chilling Effects database, as well as photo-sharing site Flickr.com's recent decision to maintain the context in which a photo was posted, even if the photo is removed. See https://www.eff.org/deeplinks/2009/09/improvingdmca-takedowns-blogger-flickr. We applaud all of these OSPs for their leadership in providing more transparency in the section 512 process.
} 
general safe harbor continue to be floated by academics and others. ${ }^{73}$ In addition to proposals to extend the section 512 model to other types of communications, a number of commentators have proposed forums of alternative dispute resolution, ${ }^{74}$ such as a small claims court, a UDRP-like online dispute resolution system, and non-judicial arbitration.

For our part, our research continues to reveal issues with fairness, balance, and accuracy that we expect to be, at least to some degree, inherent to private takedown regimes. If neither broad intermediary protection, nor takedown, satisfactorily manage online communications challenges; and if judicial review is wholly inadequate in the voluminous and fast-paced Internet; then what might serve? As noted above, research into metrics to help determine how much error is reasonable in a takedown system, and how much "play" should be tolerated, would be welcome. Such metrics could point to useful reforms to section 512, itself, or they could suggest appropriate parameters for newer policy efforts.

In general, we expect the fundamental questions raised by section 512 - where should the burdens lie when removing information from the Internet? Who should act as a gatekeeper to claims? Who should make the final decisions on takedown, and what rubric should they use to decide? - to remain important policy concerns for the foreseeable future.

\footnotetext{
${ }^{73}$ See, e.g., John Palfrey and Urs Gasser, Born Digital: Understanding the First Generation of Digital Native (2009).

74 See, e.g., Mark Lemley \& R. Anthony Reese, Reducing Digital Copyright Infringement Without Restricting Innovation, 56 Stanford L. Rev. 1345 (2004).
} 


\section{APPENDIX A: Sample Notice}

\section{Notice ID 11625}

To Whom It May Concern:

Please note that below-referenced copyright infringement notice does not substantially comply with the required notification elements of the Digital Millennium Copyright Act of 1998 ("DMCA").

Please note that we have not passed on the substantive merits of your claim.

Please visit our web site at <http://www.theplanet.com/legal $>$ www.theplanet.com/legal.

Legal Response Team

\section{THEPLANET.COM INTERNET SERVICES, INC.}

From: Admin [mailto:area52@bellsouth.net]

Sent: Monday, December 26, 2005 9:38 AM

To: n16qyy7w2sxfh9@protectfly.com; abuse@protectfly.com;

legal@theplanet.com; copyright@theplanet.com

Cc: KenM; tman@asian4you.com

Subject: RE: a4y - bitgirl / theplanet

-----Original Message-----

From: Admin [mailto:area52@bellsouth.net]

Sent: Monday, December 26, 2005 10:21 AM

To: 'n16qyy7w2sxfh9@protectfly.com'; 'abuse@protectfly.com';

'legal@theplanet.com'; 'copyright@theplanet.com'

Cc: KenM (ken@asian4you.com); 'tman@asian4you.com'

Subject: RE: a4y - bitgirl / theplanet

-----Original Message-----

From: Admin [mailto:area52@bellsouth.net]

Sent: Tuesday, December 20, 2005 2:52 PM

To: 'n16qyy7w2sxfh9@protectfly.com'; 'abuse@protectfly.com';

'legal@theplanet.com'; 'copyright@theplanet.com'

Cc: KenM (ken@asian4you.com); 'tman@asian4you.com'

Subject: a4y - bitgirl / theplanet

NOTICE of COPYRIGHT INFRINGEMENT 
Date: Dec 20, 2005

To:

WHOIS HIDDEN

traceroute to BITGIRL.INFO (67.19.79.214)

THEPLANET

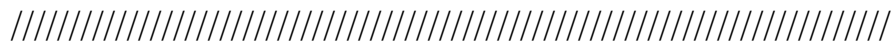

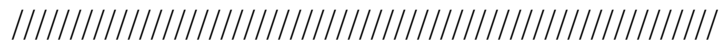

Infringing URLs:

C JP ONLINE / asian4you.com

http://www.bitgirl.info/upload/userfiles/wuyazi/1217.jpg

http://www.bitgirl.info/upload/userfiles/wuyazi/1223.jpg

ASIAN4YOU

JPONLINE Inc.

5 Jupiter House, Calleva Park

Aldermaston

Reading Berks, UK RG7 8NN

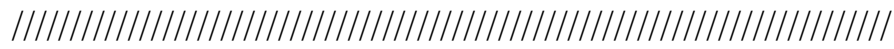

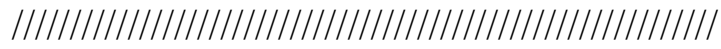

Pursuant to the Digital Millennium Copyright Act and the WIPO (World Intellectual Property Organization)

$(<\mathrm{http}: / /$ lcweb.loc.gov/copyright/legislation/dmca.pdf $>)$, this letter serves as actual notice of infringement in the event of legal proceedings.

Steve Easton is a DMCA agent, NOT an attorney. On behalf of the owner of exclusive right to the material at issue in this notice, I hereby state that I have a good faith belief that use of the material in the manner complained of is not authorized by the owner, its agent, or the law. I hereby state, under penalty of perjury under the laws of the United States, that the information in this notification is accurate, and under penalty of perjury, that the complaining party is authorized to act on behalf of the owner of an exclusive right that is being infringed as set out in this notification.

-

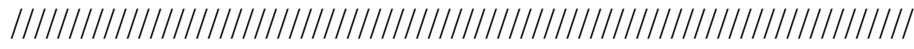




\section{APPENDIX B: \\ Example Chain of Communications Related to a Takedown Notice}

Re: FW: [EV1-C2076360W] entblog.net

To Whom It May Concern:

Please note that below-referenced copyright infringement notice does not substantially comply with the required notification elements of the Digital Millennium Copyright Act of 1998 ("DMCA").

Please note that we have not passed on the substantive merits of your claim.

Please visit our web site at www.ev1 servers.net/About/dmca.aspx

Legal Response Team

-----Original Message-----

From: [name redacted] [mailto:abuse@lambic.co.uk]

Sent: Monday, December 11, 2006 12:53 PM

To: DMCA

Subject: Re: FW: [EV1-C2076360W] entblog.net

Yes, I read that, exactly as it appears on your website. I still don't know which criteria I'm missing.

On Mon, Dec 11, 2006 at 10:59:10AM -0600, DMCA wrote:

$>$ To be effective, a Notification of Claimed Infringement must meet the

$>$ following requirements:

$>$

$>$ It must be a written communication;

$>$ It must be sent to the designated agent identified above; It must

$>$ include the following:

$>$

$>$

$>$ 1. A physical or electronic signature of a person ("Complaining

$>$ Party") authorized to act on behalf of the owner of an exclusive right

$>$ that is claimed to be infringed; 2 . Identification of the copyrighted

$>$ work claimed to have been infringed, or if multiple copyrighted works

$>$ at a single online site are covered by a single notification, a

$>$ representative list of such works at that site; 3 . Identification of 
$>$ the material that is claimed to be infringing or to be the subject of

$>$ infringing activity and that is to be removed or access to which is to

$>$ be disabled, and information reasonably sufficient to permit the

$>$ service provider to locate the material; 4. Information reasonably

$>$ sufficient to permit the service provider to contact the Complaining

$>$ Party, such as an address, telephone number, and, if available, an

$>$ electronic mail address at which the complaining party may be

$>$ contacted; 5. A statement that the Complaining Party has a good faith

$>$ belief that use of the material in the manner complained of is not

$>$ authorized by the copyright owner, its agent, or the law; and 6 . A

$>$ statement that the information in the notification is accurate, and

$>$ under penalty of perjury, that the Complaining Party is authorized to

$>$ act on behalf of the owner of an exclusive right that is allegedly

$>$ infringed.

$>$

$>$-----Original Message-----

$>$ From: [name redacted] [mailto:abuse@lambic.co.uk]

$>$ Sent: Monday, December 11, 2006 11:58 AM

$>$ To: DMCA

$>$ Subject: Re: FW: [EV1-C2076360W] entblog.net

$>$

$>$ On Mon, Dec 11, 2006 at 10:06:30AM -0600, DMCA wrote:

$>>$ Please visit our web site at www.ev1servers.net/About/dmca.aspx

$>$

$>$ I did, before I sent the complaint, and after receiving your first

$>$ message. I still don't see what information I've failed to provide.

$>$ How about you just tell me?

$>$

$>>$-----Original Message-----

$>>$ From: [name redacted] [mailto:abuse@lambic.co.uk]

$>>$ Sent: Monday, December 11, 2006 10:55 AM

$>>$ To: DMCA

$>>$ Subject: Re: FW: [EV1-C2076360W] entblog.net

$>>$

$>>$ On Mon, Dec 11, 2006 at 08:47:27AM -0600, DMCA wrote:

$>>>$ Please note that below-referenced copyright infringement notice

$>>>$ does

$>$

$>>>$ not substantially comply with the required notification elements

$>>>$ of the Digital Millennium Copyright Act of 1998 ("DMCA").

$>>$

$>>$ I believe I've included all 6 required pieces of information. What

$>>$ is missing?

$>>$

$>>$ 


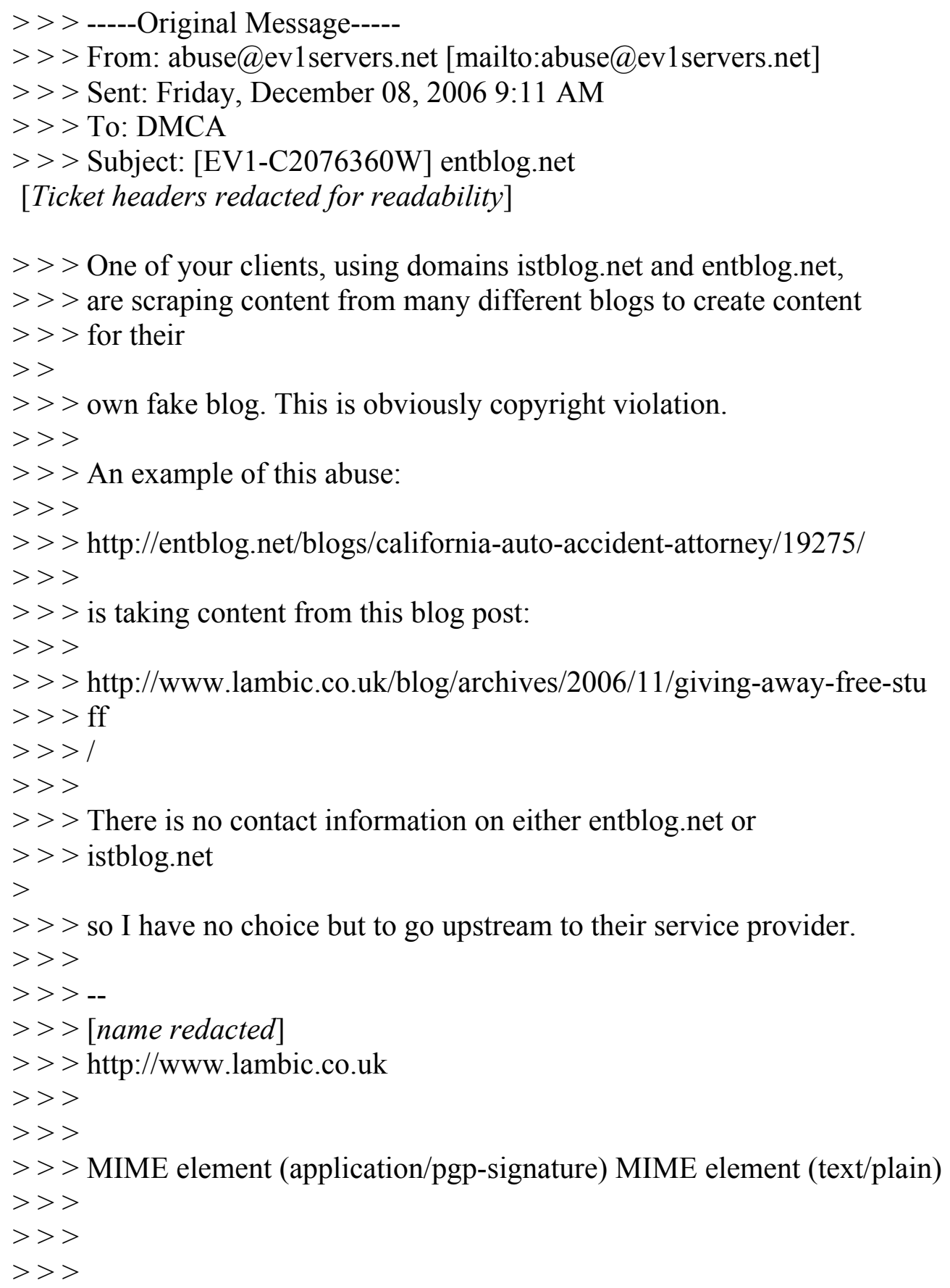




\section{APPENDIX C: Automatically Generated Infringement Reports}

Typical "Infringement Report" from Business Software Association: Notice 11826; last portion of IP address redacted

Evidentiary Information:

Notice ID: 438869

Asset: Macromedia Dreamweaver

Protocol: eDonkey

IP Address: 70.86.165.xxx

DNS: e2.a5.5646.static.theplanet.com

File Name:

Macromedia.Dreamweaver.v8.0.Incl.Keymaker-ZWT.[shareprovider.com].rar

File Size: 62492048

Timestamp: 18 Jan 2007 02:30:10 GMT

Last Seen Date: 18 Jan 2007 02:30:10 GMT

URL:

ed2k://file|Macromedia.Dreamweaver.v8.0.Incl.Keymaker-ZWT.[shareprovide

r.com].rar|62492048|30CB683E3A3BF1B14F9CFB06B9998E99|/

Username (if available):

Typical “Infringement Report” from REO SafeNet: Notice 9872; last portion of IP address redacted

Infringement Detail:

Infringing Work: The Sopranos

Filename: The.Sopranos.S06E16.HDTV.XviD-LOL.avi

First Found: 4 May 2007 03:15:02 EDT (GMT -0400)

Last Found: 4 May 2007 03:15:02 EDT (GMT -0400)

Filesize: $354,594 \mathrm{k}$

IP Address: 74.53.121.xxx

IP Port: 53521

Network: BitTorrent

Protocol: BitTorrent 